\title{
Extended dosing of darbepoetin alfa in peritoneal dialysis patients
}

\author{
Mariano Feriani ${ }^{1 *}$, Johan MJ De Meester ${ }^{2}$, Lawrence P McMahon ${ }^{3}$, Jacques B Rottembourg ${ }^{4}$, lan Bridges ${ }^{5}$, \\ Mourad Farouk ${ }^{6}$ and Wolfgang Pronai ${ }^{7}$
}

\begin{abstract}
Background: Anemia is common among peritoneal dialysis (PD) patients, and most patients require erythropoiesisstimulating agents (ESA) to maintain their hemoglobin concentrations within current guideline recommendations. Darbepoetin alfa is an ESA with a 3-fold longer half-life and greater in vivo biological activity than recombinant human erythropoietin, allowing less frequent dosing that may simplify anemia management in these patients, providing benefits to patients, care givers and health care providers. Clinical studies have confirmed the efficacy and safety of darbepoetin alfa administered at extended dosing intervals. However, there are limited data on the management of anemia with ESAs in PD patients in routine clinical practice. The aim of this multicenter observational study in European and Australian dialysis patients was to evaluate darbepoetin alfa administered once every 2 weeks (Q2W) in routine clinical practice for 12 months.

Methods: PD patients $\geq 18$ years old and converting to treatment with darbepoetin alfa Q2W were eligible for enrollment regardless of previous or current ESA use. Patients enrolled in the study were treated according to local usual clinical practice. Data were collected up to 6 months prior to and 12 months after conversion to darbepoetin alfa Q2W. The primary endpoint was hemoglobin concentration 12 months after conversion to darbepoetin alfa Q2W.
\end{abstract}

Results: Of the 741 eligible PD patients (mean age, 61 years; male, 57\%), 640 (86\%) completed the study. Mean hemoglobin concentration $(\mathrm{g} / \mathrm{dL})$ was $11.69(95 \% \mathrm{Cl}$, 11.53-11.86) 6 months before the conversion, $12.25(95 \% \mathrm{Cl}$, 12.13-12.38) at conversion, and $11.88(95 \% \mathrm{Cl}, 11.74-12.02) 12$ months after conversion to darbepoetin alfa Q2W. The weekly equivalent ESA dose $(\mu \mathrm{g} / \mathrm{wk})$ was a geometric mean of $25.24(95 \% \mathrm{Cl}, 23.46-27.15) 6$ months before conversion, $20.90(95 \% \mathrm{Cl}, 19.13-22.83)$ immediately before conversion, $18.89(95 \% \mathrm{Cl}, 18.13-19.68)$ at conversion and 19.04 (95\% Cl, 17.69-20.49) 12 months after conversion. Twelve months after conversion, $70 \%$ of patients were receiving darbepoetin alfa Q2W and 73\% had hemoglobin concentrations $>11.0 \mathrm{~g} / \mathrm{dL}$.

Conclusion: In this large observational study, PD patients were able to maintain mean hemoglobin concentrations $>11.0 \mathrm{~g} / \mathrm{dL}$ after conversion to extended dosing of darbepoetin alfa Q2W, with no mean dose increase.

\section{Background}

Anemia is a frequent and significant complication of chronic kidney disease (CKD) [1-3]. Current guidelines recommend the use of erythropoiesis-stimulating agents (ESAs) for the treatment of anemia of CKD [4-6]. Anemia management with ESAs has been associated with a reduction in clinical complications due to anemia, and may improve quality of life $[5,7,8]$.

\footnotetext{
* Correspondence: mferiani@goldnet.it

'Reparto di Nefrologia e Dialisi, Ospedale dell'Angelo, Via Pacagnella, 30174 Mestre, Italy

Full list of author information is available at the end of the article
}

Peritoneal dialysis (PD) accounts for around 18\% of renal replacement therapy in Europe, although figures differ substantially between countries $[9,10]$. Anemia is common among PD patients, and most require ESAs in order to maintain hemoglobin concentrations within guideline recommendations $[4,5,11]$.

ESAs stimulate erythropoiesis through the same mechanism as erythropoietin, the endogenous glycoprotein hormone $[3,12]$. Darbepoetin alfa (Aranesp ${ }^{\circledR}$, Amgen Inc, Thousand Oaks, CA) has an increased sialic acid-containing carbohydrate content, resulting in an approximately 3 -fold longer half-life and greater in vivo
() Biomed Central

(c) 2011 Feriani et al; licensee BioMed Central Ltd. This is an Open Access article distributed under the terms of the Creative Commons Attribution License (http://creativecommons.org/licenses/by/2.0), which permits unrestricted use, distribution, and reproduction in any medium, provided the original work is properly cited. 
biological activity than recombinant human erythropoietin (rHuEPO), consequently darbepoetin alfa can be administered at extended dosing intervals, such as up to once every 2 weeks (Q2W) for dialysis subjects or once a month for non-dialysis subjects (13-15).

Clinical trials have confirmed the efficacy and safety of darbepoetin alfa Q2W in the management of anemia in patients receiving dialysis, including those on $\mathrm{PD}$ [13-16]. However, there are few data on the actual management of anemia with ESAs in PD patients in routine clinical practice. To contribute towards establishing more data on the use of a Q2W extended dosing regimen in this setting, ALTERNATE (A Long-term Noninterventional Study to Evaluate the Effectiveness of Aranesp ${ }^{\circledR}$ in Dialysis Patients When Administered Once Every Two Weeks) was undertaken. This long-term observational study followed both hemodialysis and PD patients treated with darbepoetin alfa Q2W. In this report, we describe the PD subgroup.

\section{Methods}

This was an observational, multi-national study carried out at 344 centers in Europe and Australia. Patients $\geq 18$ years of age, undergoing routine dialysis (hemodialysis or PD) and initiating treatment with darbepoetin alfa Q2W were eligible for inclusion. All eligible patients were enrolled, and enrollment continued sequentially until the target number of patients was reached. The final patient completed the study in September 2008. Patients were excluded if they had received darbepoetin alfa in an interventional study within 6 months of converting to darbepoetin alfa Q2W, were receiving other investigational agents, or had clinical evidence of current malignancy with the exception of basal cell or squamous cell carcinoma of the skin and cervical intraepithelial neoplasia.

Data were abstracted from patient charts for up to 6 months prior to and 12 months after conversion to darbepoetin alfa Q2W. Data were abstracted retrospectively for the 6 months prior to conversion, and retrospectively and prospectively for the 12 months after conversion, depending on the date of enrolment in the study. As this was an observational study, there were no pre-specified anemia management guidelines or monitoring, and patients were treated according to the routine clinical practice in the respective treatment center. Where required by local law, the study protocol and informed consent materials were approved by the local Independent Ethics Committee, and the patients provided written informed consent prior to study entry.

\section{Statistical analysis}

For the overall study, a sample size of approximately 6000 patients was calculated as the number of patients needed for the results to have adequate precision for pre-specified patient subgroups with only $5 \%$ of the total sample $(n=312)$. The PD subset accounted for $5.1 \%$ of the total study population with over 700 enrolled patients.

In the overall study, the primary endpoint was the hemoglobin concentration 12 months after conversion to darbepoetin alfa Q2W. Secondary endpoints included the proportion of patients within European Best Practice Guidelines treatment targets for hemoglobin $(>11 \mathrm{~g} / \mathrm{dL})$ [5], ESA utilization and iron usage, hospitalization and darbepoetin alfa-related adverse drug reactions (ADRs) during the 12-month post-conversion period.

Pre-specified analyses were carried out for the PD subgroup. Continuous variables are described using mean, standard deviation (SD), 95\% 2-sided confidence intervals (CIs), median, and quartile ranges (Q1, Q3). Categorical variables are summarized as the number and percentage of patients.

Analysis of monthly hemoglobin was based on the value closest to the date of the scheduled time point (eg, month $1,2,3$ ) within a \pm 2 -week window, with the exception of the Q2W conversion time point which included values up to 8 weeks before conversion to ensure the maximum number of patients for evaluation. Intrapatient variability was calculated for each patient as the standard deviation of all monthly hemoglobin results for the period.

ESA doses were expressed as geometric means (log transformation of the data) due to the non-normal distribution of the data. Epoetin doses were converted from IU to $\mu \mathrm{g}$ using European (200:1) or Australian (200:1 SC or 240:1 IV) product label guidelines. The weekly equivalent ESA dose was calculated for individual patients for each month using all available dosing data within that month.

Analyses of endpoints included all eligible patients enrolled in the study and converted to darbepoetin alfa Q2W (full analysis set [FAS]) as observed (no imputation for missing values), regardless of subsequent change in regimen (dose, frequency, or ESA). To assess the effect of patients' withdrawal or missing data on hemoglobin concentration, a FAS last observation carried forward (LOCF) analysis was also undertaken for the primary endpoint. Additional post-hoc analyses were undertaken to assess hemoglobin and dose levels in patients treated with darbepoetin alfa only prior to conversion to darbepoetin alfa Q2W, and whether the inclusion of ESA-naïve subjects affected the mean dose and hemoglobin levels. All statistical analyses were performed with SAS/STAT software (version 8.2, SAS Institute Inc., Cary, NC, USA).

The ALTERNATE database and statistical analyses were managed by the study sponsor. 


\section{Results}

A total of 742 PD patients were enrolled and 741 were eligible for the study from 172 centers in 14 European countries $(n=593)$ and Australia $(n=148)$. One patient was ineligible as age was not confirmed as $\geq 18$ years. Six hundred and forty patients completed the study (86.4\%); the main reasons for discontinuation were kidney transplant $(\mathrm{n}=39)$, and death $(\mathrm{n}=36)$ (Table 1$)$.

Patient demographics and characteristics at conversion are shown in Table 2 . Immediately before conversion, most patients were receiving darbepoetin alfa (76.1\%), and most had a weekly (QW) ESA regimen (78.4\%). In total, $8.9 \%$ of patients had not received an ESA in the 6 months prior to conversion to darbepoetin alfa Q2W (including ESA-naïve patients and patients who stopped ESA therapy for 6 months or more).

\section{Hemoglobin and ESA dose}

The mean hemoglobin concentration 6 months prior to conversion to darbepoetin Q2W was 11.69 (95\% CI, $11.53-11.86) \mathrm{g} / \mathrm{dL}$, trending upwards to 12.25 (95\% CI, 12.13-12.38) $\mathrm{g} / \mathrm{dL}$ at conversion (Figure 1) in the FAS. At month 12 after conversion, the mean hemoglobin concentration was 11.88 (95\% CI, 11.74-12.02) g/dL (Figure 1) in the FAS and 11.83 (95\% CI, 11.72-11.94) g/ $\mathrm{dL}$ in the LOCF analysis.

Most patients (73.0\%) achieved a hemoglobin concentration $>11 \mathrm{~g} / \mathrm{dL}$ at month 12 (Figure 2), which was similar to the proportion of patients 6 months prior to conversion (69.3\%) and at conversion (76.2\%). The proportion of patients achieving a hemoglobin concentration $>11$ and $\leq 13 \mathrm{~g} / \mathrm{dL}$ was $52.5 \% 6$ months prior to conversion, $43.7 \%$ at conversion, and $54.0 \%$ at month 12 .

Mean intrapatient variability in hemoglobin was reduced following conversion to darbepoetin alfa Q2W, from $0.79 \mathrm{~g} / \mathrm{dL}$ and $0.90 \mathrm{~g} / \mathrm{dL} 6$ to 4 months and 1 to 3 months prior to conversion, respectively, to $0.71 \mathrm{~g} / \mathrm{dL}$, $0.65 \mathrm{~g} / \mathrm{dL}, 0.70 \mathrm{~g} / \mathrm{dL}$, and $0.65 \mathrm{~g} / \mathrm{dL}$ in the 3 -month periods from 1 to 12 months after conversion.

Table 1 Subject disposition

\begin{tabular}{lc}
\hline & $\mathbf{n}(\%)$ \\
\hline Eligible subjects (full analysis set) & 741 \\
Subjects who completed study & $640(86.4)$ \\
Subjects who discontinued study & $101(13.6)$ \\
$\quad$ Kidney transplant & $39(38.6)^{\mathrm{a}}$ \\
Death & $36(35.6)^{\mathrm{a}}$ \\
No longer treated at clinic & $15(14.9)^{\mathrm{a}}$ \\
Consent withdrawn & $1(1.0)^{\mathrm{a}}$ \\
Other & $10(9.9)^{\mathrm{a}}$ \\
\hline
\end{tabular}

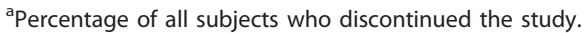

The calculated weekly dose of ESA decreased from a geometric mean of 25.24 (95\% CI, 23.46-27.15) $\mu \mathrm{g} / \mathrm{wk}$ 6 months prior to conversion to 20.90 (95\% CI, 19.1322.83) $\mu \mathrm{g} / \mathrm{wk}$ the day before conversion. At conversion, the calculated first dose of darbepoetin alfa was a geometric mean of 18.89 (95\% CI, 18.13-19.68) $\mu \mathrm{g} /$ wk, and 19.04 [95\% CI, 17.69-20.49] $\mu \mathrm{g} / \mathrm{wk}$ at month 12 (Figure 1). Similar results were observed when only subjects treated with darbepoetin alfa prior to conversion ( $\mathrm{n}=564)$ were analyzed, or when ESA-naïve patients $(n=66)$ were excluded from the analyses [data not shown].

ESA dose remained unchanged in $65.7 \%$ and $63.8 \%$ of patients in months 1 to 6 , and 7 to 12 after conversion, respectively, compared with $71.7 \%$ in the 6 months prior to conversion to darbepoetin alfa Q2W. ESA dosing frequency remained unchanged in $79.8 \%$ and $74.5 \%$ of patients in months 1 to 6 , and 7 to 12 after conversion, respectively, compared with $82.8 \%$ in the 6 months prior to conversion. Of those patients who had changes in dose and/or frequency, most patients $(88 \%)$ had 1 or 2 changes. At month $12,70.0 \%$ of patients were receiving darbepoetin alfa Q2W and 5.5\% of patients were receiving darbepoetin alfa once a month (Table 3).

\section{Laboratory values}

C-reactive protein (CRP) and iron levels were stable over the study (Figure 2). In patients whose hemoglobin levels were $>11 \mathrm{~g} / \mathrm{dL}$ for at least $60 \%$ of the time following conversion, median (Q1, Q3) CRP levels were lower than in patients with these hemoglobin levels for $<60 \%$ of the time $(6.0[2.9,14.0]$ vs. $9.0[3.5,21.4] \mathrm{mg} / \mathrm{L})$.

Between $43.2 \%$ and $46.6 \%$ of patients were on iron therapy in any 3-month period during the study (Figure 2). Of those patients on iron therapy, about $60 \%$ of patients were receiving oral iron therapy.

\section{Hospitalizations}

During the 12 months after conversion to darbepoetin alfa Q2W, 52.0\% of patients were hospitalized with a mean duration of 18.8 days (median 14.0 days). The primary reasons for hospitalization included infection (40.3\%), and hyperkalemia/electrolyte disorders (25.7\%), although most reasons for hospitalization were listed as 'other' (51.7\%) (Figure 3).

\section{Safety}

The ADR rate was low during the 12 months after conversion to darbepoetin alfa Q2W, with no unexpected events emerging. A total of 6 ADRs were reported in 4 patients $(0.5 \%)$. These included myalgia $(n=2)$, hypertension $(n=1)$, injection site pain $(n=1)$, muscular weakness $(n=1)$, and $\operatorname{rash}(n=1)$. A total of 36 patients $(4.9 \%)$ were withdrawn from the study due to 
Table 2 Subject demographics and characteristics at conversion to darbepoetin alfa Q2W

\begin{tabular}{|c|c|}
\hline & $n=741$ \\
\hline \multicolumn{2}{|l|}{ Sex, n (\%) } \\
\hline Female & $318(42.9)$ \\
\hline Male & $421(56.8)$ \\
\hline Not recorded & $2(0.3)$ \\
\hline Age (years), mean (SD) & $61.2(15.2)$ \\
\hline \multicolumn{2}{|l|}{ Age (years), n (\%) } \\
\hline$<65$ & $413(55.7)$ \\
\hline$\geq 65$ & $328(44.3)$ \\
\hline \multicolumn{2}{|l|}{ Primary cause of CKD, n (\%) } \\
\hline Diabetes mellitus & $140(18.9)$ \\
\hline Glomerulonephritis & $139(18.8)$ \\
\hline Hypertension & $137(18.5)$ \\
\hline Unknown etiology & $108(14.6)$ \\
\hline Polycystic kidney/hereditary disease & $67(9.0)$ \\
\hline Interstitial nephropathy/obstructive nephropathy & $63(8.5)$ \\
\hline Tumors & $6(0.8)$ \\
\hline Other & $81(10.9)$ \\
\hline Duration of dialysis (years), mean (SD) & $3.1(3.6)$ \\
\hline \multicolumn{2}{|l|}{ Duration of dialysis (years), n (\%) } \\
\hline$<2$ years & $231(31.2)$ \\
\hline $2-5$ years & $429(57.9)$ \\
\hline$>5$ years & $81(10.9)$ \\
\hline History of cardiovascular disease, n (\%) & $379(51.1)$ \\
\hline History of diabetes, n (\%) & $210(28.3)$ \\
\hline Type 1 & $30(4.0)$ \\
\hline Type 2 & $173(23.3)$ \\
\hline Diabetic, type not recorded & $7(0.9)$ \\
\hline Duration of ESA use (years), mean (SD) & $2.8(2.0)$ \\
\hline \multicolumn{2}{|l|}{$\mathrm{Hb}$ concentration at conversion, $\mathrm{g} / \mathrm{dL}, \mathrm{n}(\%)$} \\
\hline$\leq 11$ & $167(22.5)$ \\
\hline$>11-13$ & $307(41.4)$ \\
\hline$>13$ & $228(30.8)$ \\
\hline Not recorded & $39(5.3)$ \\
\hline \multicolumn{2}{|l|}{ ESA treatment prior to conversion, $\mathrm{n}(\%)$} \\
\hline Darbepoetin alfa & $564(76.1)$ \\
\hline Epoetin alfa & $19(2.6)$ \\
\hline Epoetin beta & $92(12.4)$ \\
\hline ESA naïve ${ }^{b}$ & $66(8.9)$ \\
\hline \multicolumn{2}{|l|}{ ESA frequency prior to conversionc, $n(\%)$} \\
\hline TIW or BIW & $20(3.0)$ \\
\hline QW & $529(78.4)$ \\
\hline Other & $124(18.4)$ \\
\hline Not recorded & $2(0.3)$ \\
\hline \multicolumn{2}{|l|}{ ESA route prior to conversionc, $\mathrm{n}(\%)$} \\
\hline IV & $41(6.1)$ \\
\hline SC & $634(93.9)$ \\
\hline \multicolumn{2}{|l|}{ Darbepoetin alfa route at conversion, $\mathrm{n}(\%)$} \\
\hline IV & $24(3.2)$ \\
\hline SC & $717(96.8)$ \\
\hline
\end{tabular}

Table 2 Subject demographics and characteristics at conversion to darbepoetin alfa Q2W (Continued)

\begin{tabular}{|c|c|}
\hline \multicolumn{2}{|l|}{ Darbepoetin alfa weekly dose at conversion, $\mu \mathrm{g} / \mathrm{wk}$} \\
\hline Geometric mean $(95 \% \mathrm{Cl})$ & $18.89(18.13-19.68)$ \\
\hline \multicolumn{2}{|l|}{ Iron status, n (\%) } \\
\hline $\begin{array}{l}\text { Serum ferritin }>100 \mu \mathrm{g} / \mathrm{L} \text { and either } \\
\text { TSAT }>20 \% \text { or hypochromic red cells }<10 \%\end{array}$ & $255(34.4)$ \\
\hline $\begin{array}{l}\text { Serum ferritin } \leq 100 \mu \mathrm{g} / \mathrm{L} \text { or both } \\
\text { TSAT } \leq 20 \% \text { and hypochromic red cells } \geq 10 \%\end{array}$ & $161(21.7)$ \\
\hline Not recorded & $325(43.9)$ \\
\hline
\end{tabular}

${ }^{a} n=718$; ${ }^{b}$ received no ESA in the 6 months prior to conversion; ${ }^{c}$ percentages calculated excluding ESA-naïve patients.

Abbreviations: BIW, twice a week; $\mathrm{Cl}$, confidence interval; $\mathrm{CKD}$, chronic kidney disease; ESA, erythropoiesis-stimulating agent; $\mathrm{Hb}$, hemoglobin; IV

intravenous; QW, once a week; Q2W, every two weeks; SC, subcutaneous; SD, standard deviation; TIW, three times a week; TSAT, transferrin saturation.

death, but these deaths were considered unrelated to darbepoetin alfa by the investigators.

\section{Discussion}

Currently, ALTERNATE is the largest observational study of ESA use in dialysis patients in Europe and Australia, and includes a relatively large number of PD patients. The results of this analysis in PD patients indicate that despite reducing the frequency of administration, patients converted to darbepoetin alfa Q2W had a mean hemoglobin concentration $>11.0 \mathrm{~g} / \mathrm{dL} 12$ months after conversion, without requiring an increase in mean dose. Moreover, $70 \%$ of patients were receiving darbepoetin alfa Q2W at month 12 , indicating that most $\mathrm{PD}$ patients were successfully maintained on extended dosing frequency.

In order to recruit a large, diverse population, our study had few eligibility criteria. This study included patients who were ESA naïve, and patients who converted from other ESAs and dosing regimens. Indeed, the characteristics and hemoglobin concentrations at conversion were similar to the Netherlands Cooperative Study on the Adequacy of Dialysis, which included 480 PD patients [17]. This suggests that our patient population is typical of European PD patients, and the treatment practices observed are representative of the PD population. Hospitalizations were frequently reported in our study, which is typical of a dialysis population, and the types of ADRs related to darbepoetin alfa were consistent with those reported in controlled trials of dialysis patients receiving darbepoetin alfa $[13,14,16]$. Our study reports that hemoglobin concentrations can be maintained $>11 \mathrm{~g} / \mathrm{dL}$ without an increase in mean dose after conversion to extended (Q2W) darbepoetin alfa dosing in clinical practice. These results are consistent with randomized controlled trials of extended Q2W dosing 


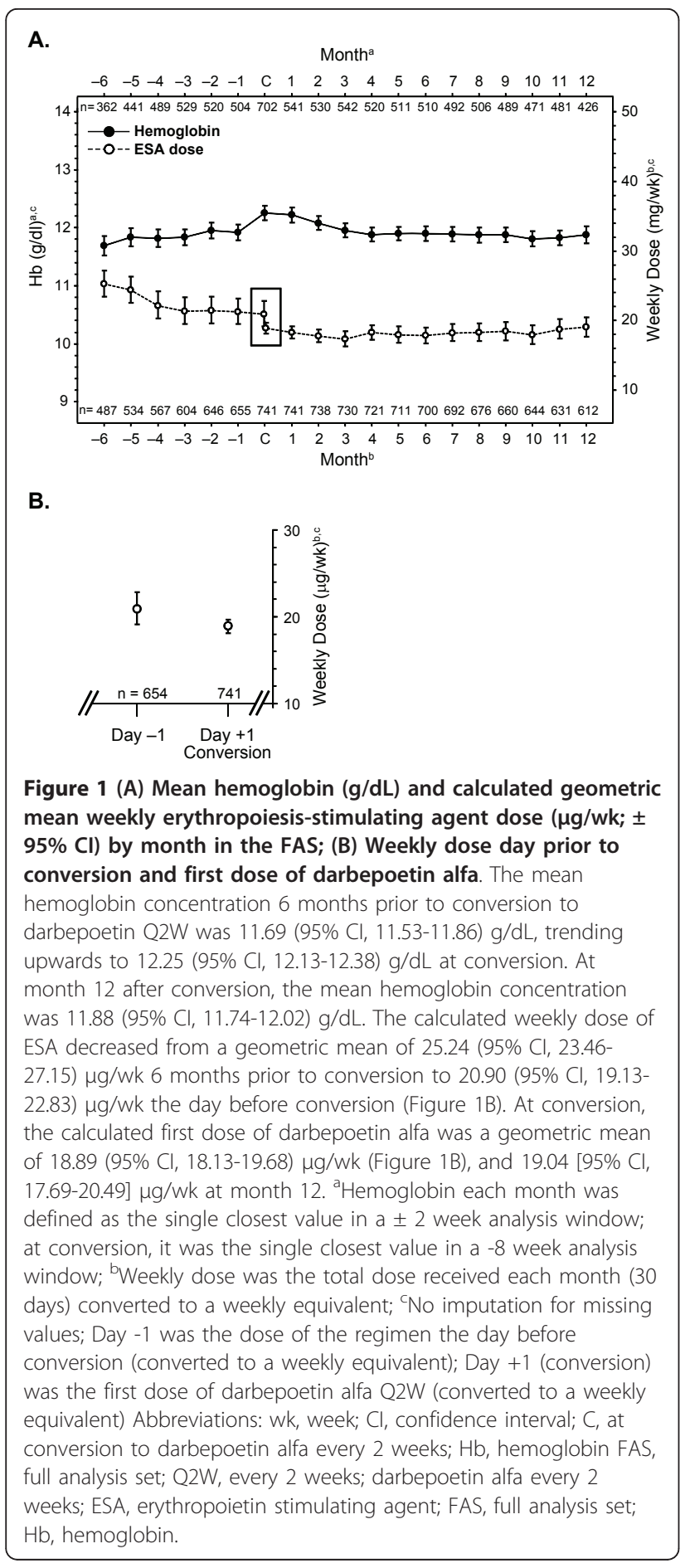

of darbepoetin alfa in dialysis patients (hemodialysis and PD patients) $[5,16,18]$, and several smaller studies in PD patients $[14,15,19]$. Data from a pooled subanalysis of eight trials also reported that PD patients can be switched from epoetin alfa or beta to darbepoetin alfa Q2W regimen without a dose increase and with maintenance of hemoglobin concentrations [20].
Iron stores were within the European guideline targets in most patients and up to $47 \%$ of patients in any 3 -month period were prescribed iron supplementation in this study [5]. Iron deficiency was reported in 39\% of patients with sufficient data to assess iron deficiency at conversion. This is of concern as iron deficiency can inhibit the response to ESAs, and regular assessment is recommended by European guidelines [5,11].

An upwards trend in hemoglobin concentration was observed prior to conversion to darbepoetin alfa Q2W. This may provide insight into the reasons for conversion to an extended dosing regimen, with physicians less likely to change an existing treatment regimen in patients with well controlled hemoglobin, than in patients who have rising hemoglobin. In addition, hemoglobin was not stable in many patients in the 3 months prior to conversion, as reflected in the intrapatient variation, which may have influenced the decision to switch. The data also indicate a reduction in dose at conversion, which could suggest that these patients do not receive the equivalent dosage when converted to an extended dosing regimen, resulting in a lower hemoglobin after conversion.

Extended dosing may be advantageous in the management of anemia in PD patients as it reduces the frequency of ESA administration and may enable alignment of ESA administration with routine clinic visits, especially since PD patients as a group are not seen as often by health care providers as hemodialysis patients [15]. This could reduce both the number of visits and injections required by a patient each month, and decrease the potential for injection site pain, which may increase patient satisfaction and improve adherence to treatment [21-23]. ESA management is also labor intensive and time consuming for health care providers, requiring frequent hemoglobin monitoring to ensure that guideline targets are maintained, dose changes for hemoglobin variation above guideline ranges, and depending on the ESA half-life, administration up to three times a week to maintain appropriate hemoglobin concentrations [23]. Thus, extended dosing may simplify anemia management for patients, care givers, and health care providers. Our study indicates that PD patients can be successfully converted to an extended dosing regimen, with $70 \%$ of patients receiving darbepoetin alfa Q2W at month 12 .

There are a number of potential limitations to this study. As this was an observational study, there were no anemia management guidelines or monitoring, therefore there may have been differences in hemoglobin targets and reimbursement for the management of renal anemia in individual centers and countries. Additionally, there was no control group or randomization, which limits the statistical assessment of the data. There may have been 

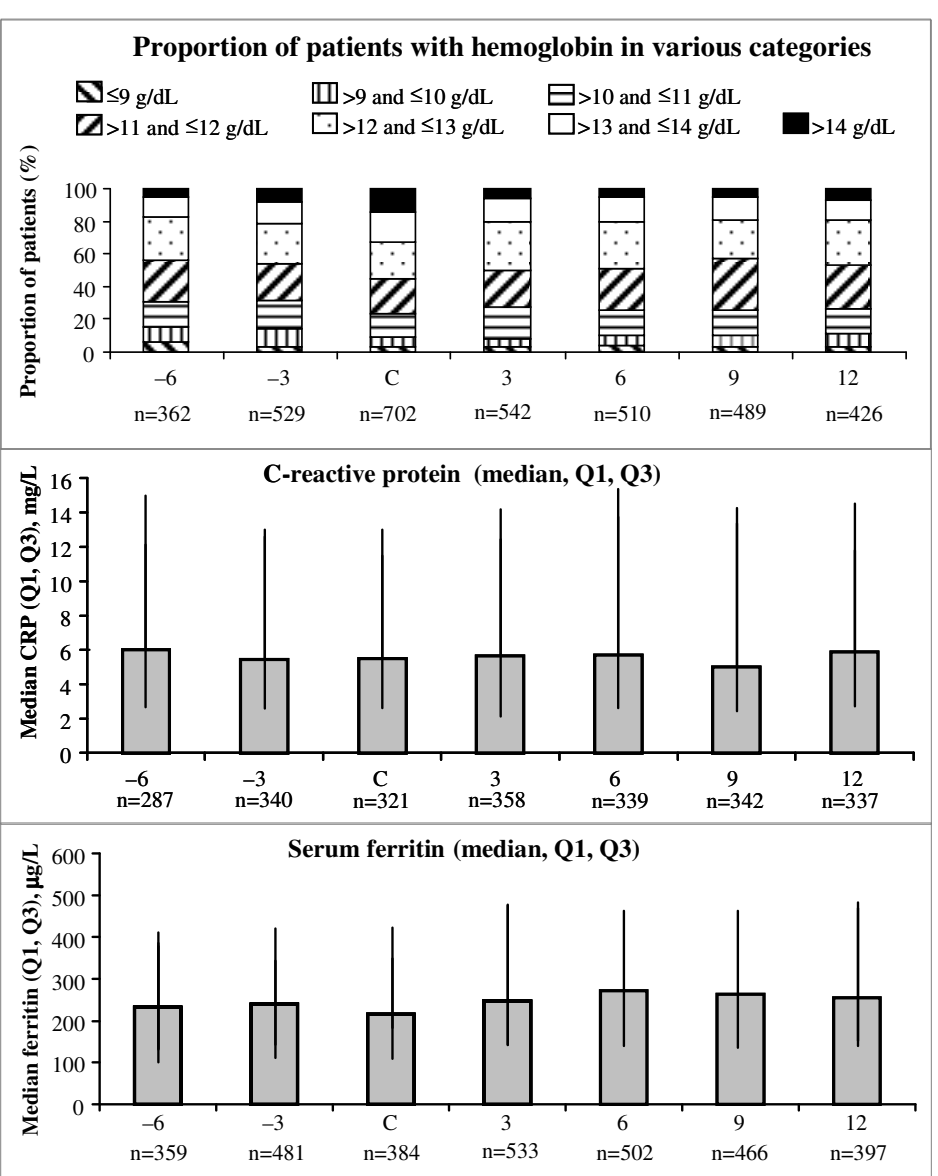

TSAT (median Q1, Q3)
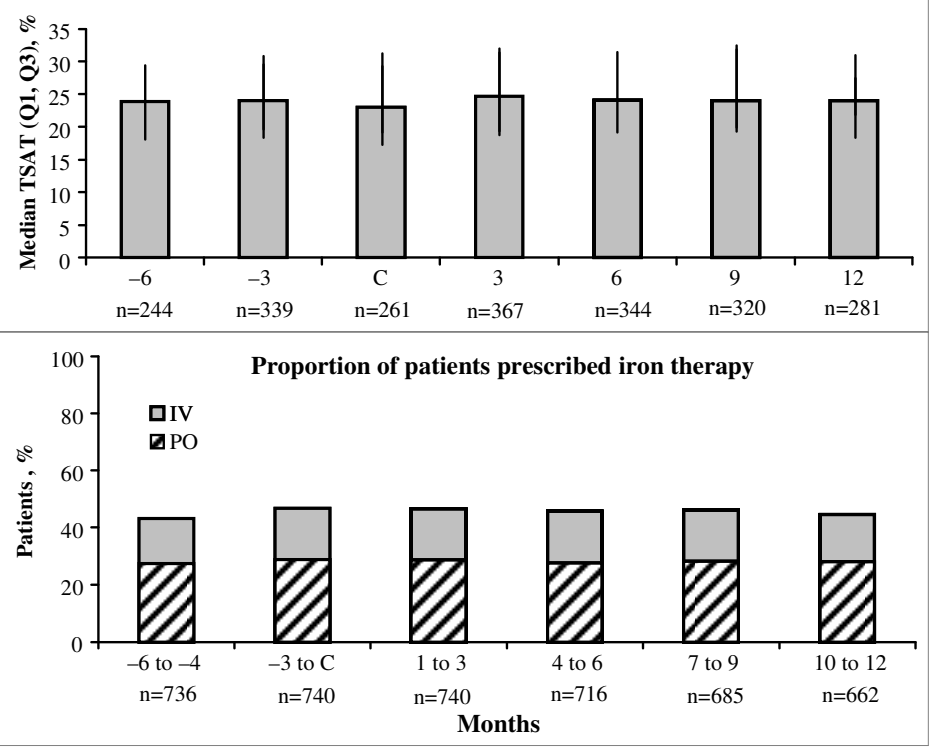

Figure 2 Proportion of patients with hemoglobin concentration in various categories, C-reactive protein (CRP) levels, iron stores and usage before and after conversion to darbepoetin alfa Q2W. Most patients (73.0\%) achieved a hemoglobin concentration $>11 \mathrm{~g} / \mathrm{dL}$ at month 12, which was similar to the proportion of patients 6 months prior to conversion (69.3\%) and at conversion (76.2\%). The proportion of patients achieving a hemoglobin concentration $>11$ and $\leq 13 \mathrm{~g} / \mathrm{dL}$ was $52.5 \% 6$ months prior to conversion, $43.7 \%$ at conversion, and $54.0 \%$ at month 12. CRP and iron levels were stable over the study. Between $43.2 \%$ and $46.6 \%$ of patients were on iron therapy in any 3 -month period during the study. Of those patients on iron therapy, about $60 \%$ of patients were receiving oral iron therapy. Abbreviations: $C$, at conversion to darbepoetin alfa every 2 weeks; CRP, C-reactive protein; PO, oral; IV, intravenous; Q1-Q3, quartile ranges; TSAT, transferrin saturation. 
Table 3 Erythropoiesis-stimulating agent type and frequency at month 12 for peritoneal dialysis patients who initiated darbepoetin alfa Q2W treatment

\begin{tabular}{lccc}
\hline Frequency & \multicolumn{3}{c}{ ESA Type $(\mathbf{n}=\mathbf{6 1 6})$} \\
\hline Total & $\begin{array}{c}\text { Darbepoetin alfa } \\
\mathbf{n}(\%)\end{array}$ & $\begin{array}{c}\text { Epoetin alfa } \\
\mathbf{n}(\%)\end{array}$ & $\begin{array}{c}\text { Epoetin beta } \\
\mathbf{n}(\%)\end{array}$ \\
TIW/BIW & $594(96.4 \%)$ & $13(2.1 \%)$ & $9(1.5 \%)$ \\
QW & $5(0.8 \%)$ & $5(0.8 \%)$ & $2(0.3 \%)$ \\
Q2W & $94(15.3 \%)$ & $3(0.5 \%)$ & $4(0.6 \%)$ \\
QM & $431(70.0 \%)$ & - & - \\
Other & $34(5.5 \%)$ & - & - \\
\hline
\end{tabular}

Abbreviations: BIW, twice a week; QW, once weekly; Q2W, once every other week; QM, once monthly; TIW, three times a week.

selection bias for patients included in our study, however, the eligibility criteria was aimed at recruiting a wide, diverse population, and the study protocol required patient enrollment to be sequential, therefore centers could not select specific patients. As noted above, the results of this study indicate that the decision to convert to darbepoetin alfa Q2W may have been biased toward patients with increasing hemoglobin prior to conversion. This may reflect the underlying reasons for conversion to an extended dosing regimen, rather than an inherent bias. ESA-naive patients were also included in the analysis, but post-hoc analysis indicated that they did not impact the results. As observational studies may be limited by missing data points, we included a sensitivity analysis in which the data were analyzed by applying LOCF

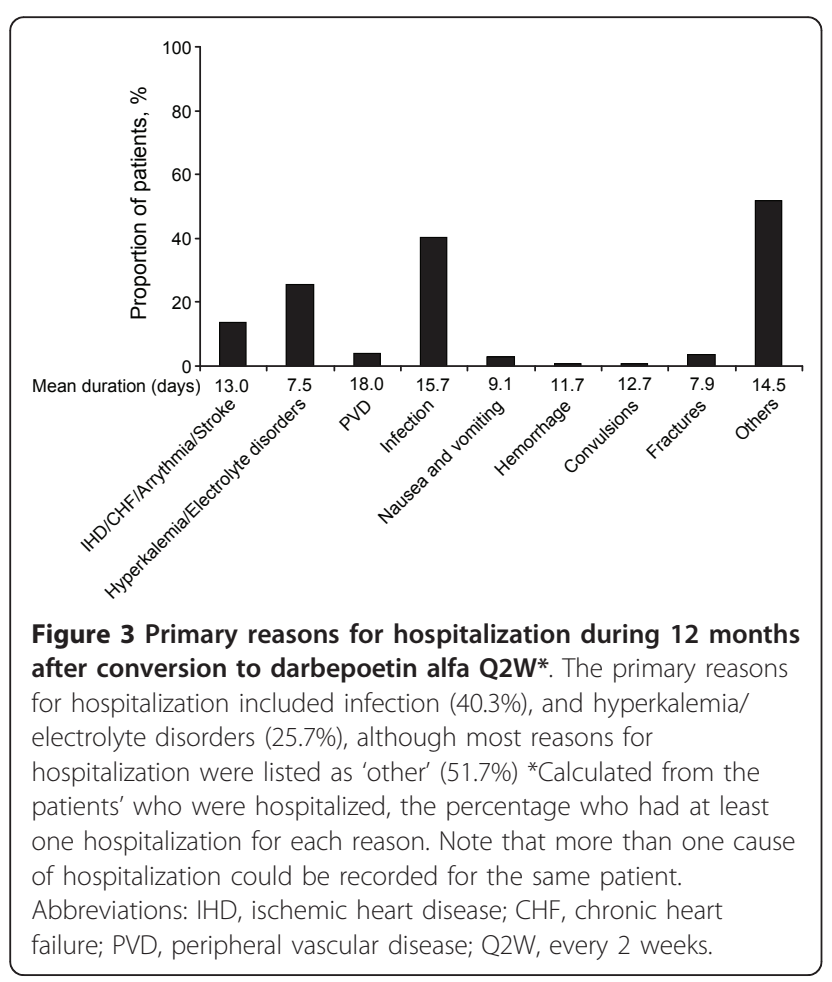

imputation to evaluate the effects of missing values and changes in ESA treatment after conversion to darbepoetin alfa Q2W; results were comparable.

In March 2008, during the ALTERNATE study, the label changed for darbepoetin alfa in Europe. The recommended hemoglobin target was changed from $>11.0 \mathrm{~g} / \mathrm{dL}$ (with an individualised upper limit of $<14.0 \mathrm{~g} / \mathrm{dL}$ ) to a target of 10.0-12.0 g/dL for all patients. Therefore the data for patients achieving the previously recommended hemoglobin target of $>11.0 \mathrm{~g} / \mathrm{dL}$ are no longer exactly aligned with current targets, and these results may give the appearance that patients were not achieving target ranges.

\section{Conclusions}

Results from this observational study with darbepoetin alfa indicate that PD patients can successfully maintain hemoglobin concentrations within guideline targets in a clinical practice setting without an increase in the mean dosage using a darbepoetin alfa Q2W regimen, and provides insights into the treatment practices of PD patients receiving ESAs.

\section{Acknowledgements}

The authors wish to thank the participating dialysis centers and investigators for contributions to the study and data collection. We also wish to thank Dikran Toroser (Amgen Inc.) and Mandy Suggitt (on behalf of Amgen, Inc.) for medical writing assistance; Tony Mossman (Amgen, Cambridge, UK) for statistical support. The study was funded by Amgen (Europe) $\mathrm{GmbH}$. Amgen (Europe) $\mathrm{GmbH}$ and Amgen Inc. participated in the study design, data collection and analysis, provided editorial support, and participated in the discussions for submission of the manuscript with the authors.

\section{Author details \\ 'Reparto di Nefrologia e Dialisi, Ospedale dell'Angelo, Via Pacagnella, 30174 Mestre, Italy. ${ }^{2}$ Department of Nephrology \& Dialysis, AZ, Nikolaas, Moerlandstraat 1, 9100 Sint-Niklaas, Belgium. ${ }^{3}$ Director, Department of Renal Medicine, Eastern Health, c/- Arnold Street, Box Hill 3128, Victoria, Australia. ${ }^{4}$ Dialysis Unit, Centre Suzanne Levy, Paris 75011, France. ${ }^{5}$ Biostatistics, Amgen Ltd, 240 Cambridge Science Park, Milton Road, Cambridge, CB4 OWD, UK. ${ }^{6}$ Clinical Development, Amgen (Europe) GmbH, Dammstrasse 23, 6300 Zug, Switzerland. ${ }^{7}$ Department of Internal Medicine, Hemodialysis, Barmherzige Brüder Eisenstadt, Esterhazystrasse 26, A-7000 Eisenstadt, Austria.}

\section{Authors' contributions}

MF has contributed to the data analysis, drafting/revising the content of the manuscript, and read and approved the final manuscript; JDM has contributed to the data acquisition/analysis, drafting/revising the content of the manuscript, and read and approved the final manuscript. LM has contributed to the data acquisition/analysis, drafting/revising the content of the manuscript, and read and approved the final manuscript; JR has contributed to the data acquisition/analysis, drafting/revising the content of the manuscript, and read and approved the final manuscript; IB has contributed to the data acquisition/analysis, drafting/revising the content of the manuscript, and read and approved the final manuscript; MF has contributed to the data acquisition/analysis, drafting/revising the content of the manuscript, and read and approved the final manuscript; WP has contributed to the data acquisition/analysis, drafting/revising the content of the manuscript, and read and approved the final manuscript.

\section{Competing interests}

This study was funded and sponsored by Amgen (Europe) GmbH. Drs Mariano Feriani, Johan MJ De Meester, Lawrence P. McMahon, Wolfgang 
Pronai and Jacques B Rottembourg are members of the ALTERNATE Steering Committee. Dr Johan MJ De Meester has received consultancy fees and speaker fees, and Dr Lawrence P McMahon has received consultancy fees from Amgen. lan Bridges and Mourad Farouk are employees of Amgen (Europe) $\mathrm{GmbH}$.

Received: 4 October 2010 Accepted: 24 March 2011 Published: 24 March 2011

\section{References}

1. Astor BC, Muntner P, Levin A, Eustace JA, Coresh J: Association of kidney function with anemia: the Third National Health and Nutrition Examination Survey (1988-1994). Arch Intern Med 2002, 162(12):1401-1408.

2. Hsu CY, McCulloch CE, Curhan GC: Epidemiology of anemia associated with chronic renal insufficiency among adults in the United States: results from the Third National Health and Nutrition Examination Survey. J Am Soc Nephrol 2002, 13(2):504-510.

3. Tong EM, Nissenson AR: Erythropoietin and anemia. Semin Nephrol 2001, 21(2):190-203.

4. KDOQI: KDOQI Clinical Practice Guideline and Clinical Practice Recommendations for anemia in chronic kidney disease: 2007 update of hemoglobin target. Am J Kidney Dis 2007, 50(3):471-530.

5. Locatelli F, Aljama P, Barany P, Canaud B, Carrera F, Eckardt KU, Horl WH, Macdougal IC, Macleod A, Wiecek A, et al: Revised European best practice guidelines for the management of anaemia in patients with chronic renal failure. Nephrol Dial Transplant 2004, 19(Suppl 2):ii1-47.

6. Pollock CA: The impact of guidelines for the prevention of anemia on clinical outcome. Perit Dial Int 2005, 25(Suppl 3):S99-101.

7. Besarab A, Bolton WK, Browne JK, Egrie JC, Nissenson AR, Okamoto DM, Schwab SJ, Goodkin DA: The effects of normal as compared with low hematocrit values in patients with cardiac disease who are receiving hemodialysis and epoetin. N Engl J Med 1998, 339(9):584-590.

8. Revicki DA, Brown RE, Feeny DH, Henry D, Teehan BP, Rudnick MR, Benz RL: Health-related quality of life associated with recombinant human erythropoietin therapy for predialysis chronic renal disease patients. Am J Kidney Dis 1995, 25(4):548-554.

9. ERA-EDTA Registry: ERA-EDTA Registry 2007 Annual Report. Academic Medical Center, Department of Medical Informatics Amsterdam, The Netherlands; 2009.

10. Lo WK: Peritoneal dialysis utilization and outcome: what are we facing? Perit Dial Int 2007, 27(Suppl 2):S42-47.

11. Macdougall IC: How to optimise anaemia therapy in peritoneal dialysis patients. Contrib Nephrol 2006, 150:202-213.

12. Macdougall IC: Novel erythropoiesis stimulating protein. Semin Nephrol 2000, 20(4):375-381.

13. Brunkhorst R, Bommer J, Braun J, Haag-Weber M, Gill C, Wagner J, Wagener T: Darbepoetin alfa effectively maintains haemoglobin concentrations at extended dose intervals relative to intravenous or subcutaneous recombinant human erythropoietin in dialysis patients. Nephrol Dial Transplant 2004, 19(5):1224-1230.

14. Fang YW, Chang $\mathrm{CH}$ : Subcutaneous administration of darbepoetin alfa effectively maintains hemoglobin concentrations at extended dose intervals in peritoneal dialysis patients. Perit Dial Int 2009, 29(2):199-203.

15. Mahajan S, Boulton H, Gokal R: A trial of subcutaneous administration of darbepoetin alfa once every other week for the treatment of anemia in peritoneal dialysis patients. J Nephrol 2004, 17(5):687-692.

16. Vanrenterghem Y, Barany P, Mann JF, Kerr PG, Wilson J, Baker NF, Gray SJ: Randomized trial of darbepoetin alfa for treatment of renal anemia at a reduced dose frequency compared with rHuEPO in dialysis patients. Kidney Int 2002, 62(6):2167-2175.

17. Termorshuizen F, Korevaar JC, Dekker FW, Van Manen JG, Boeschoten EW, Krediet RT: Hemodialysis and peritoneal dialysis: comparison of adjusted mortality rates according to the duration of dialysis: analysis of The Netherlands Cooperative Study on the Adequacy of Dialysis 2. J Am Soc Nephrol 2003, 14(11):2851-2860.

18. Mann J, Kessler M, Villa G, et al: Aranesp (darbepoetin alfa) once every 2 weeks (Q2W) effectively maintains haemoglobin $(\mathrm{Hb})$ levels in dialysis patients: a pooled analysis of 8 clinical studies. Nephrol Dial Transplant 2005, 20(suppl 5):v263-264

19. Bajo MA, Perez Fontan M, Remon C, Sanchez-Tomero JA, Llados F, Selgas R: Changing the frequency of administration of darbepoetin alfa (from weekly to fortnightly) maintains the haemoglobin levels in patients undergoing peritoneal dialysis. Nefrologia 2009, 29(2):136-142.

20. Mann J, Kessler M, Villa G, Martinez-Castelao A, Feldt-Rasmussen B, Cruz J, Horl WH, Mattin C, Praml C, Wilkie M: Darbepoetin alfa once every 2 weeks for treatment of anemia in dialysis patients: a combined analysis of eight multicenter trials. Clin Nephrol 2007, 67(3):140-148.

21. Lo WK: Latest strategy in renal anemia management in peritoneal dialysis patients. Perit Dial Int 2008, 28(Suppl 3):S76-80.

22. Richter A, Anton SE, Koch P, Dennett SL: The impact of reducing dose frequency on health outcomes. Clin Ther 2003, 25(8):2307-2335, discussion 2306.

23. Roger SD: Extended administration of erythropoiesis-stimulating agents for optimising the management of renal anaemia: what is the evidence? Int J Clin Pract 2008, 62(9):1413-1422.

\section{Pre-publication history}

The pre-publication history for this paper can be accessed here: http://www.biomedcentral.com/1471-2369/12/13/prepub

doi:10.1186/1471-2369-12-13

Cite this article as: Feriani et al.: Extended dosing of darbepoetin alfa in peritoneal dialysis patients. BMC Nephrology 2011 12:13.

\section{Submit your next manuscript to BioMed Central and take full advantage of:}

- Convenient online submission

- Thorough peer review

- No space constraints or color figure charges

- Immediate publication on acceptance

- Inclusion in PubMed, CAS, Scopus and Google Scholar

- Research which is freely available for redistribution

Submit your manuscript at www.biomedcentral.com/submit
C Biomed Central 